\section{The Value of Life: an Introduction to Medical Ethics}

John Harris, London, xviii +281 pages, £7.95 paperback, Routledge and Kegan Paul, 1985.

Like all John Harris's work, this survey and proposed solution of some of the central problems in medical ethics, especially life and death issues, is brilliantly argued (always) and highly controversial (sometimes). Both characteristics stem from the fact that the book proceeds with strict consistency from the plausible - but by no means inevitable - unexpressed premiss that the only possible source of ethical values lies in what is actually found valuable. Thus freedom from suffering is valued by all sentient creatures, whether or not they can formulate their values and desires in words; and so we are morally obliged to cause as little pain as possible to humans or animals. But life can be valued only by a person, ie by a being that is capable of being self-conscious and of knowing it has a life to value; hence we must respect the lives of human beings already born, but not of plants, animals or human fetuses.

Now, if what is valuable is the same as what is valued, two values will be of supreme importance, because they are necessary conditions for realising all other values. These are the life and the autonomy, ie capacity for free choice, of persons. Hence the obligation to respect their life and autonomy is overriding, and extends to those who are currently not able to exercise personhood but may be reasonably expected to do so in the future, such as children or those temporarily unconscious. Moreover, the lives of all persons are equally important, since no external criteria exist to make their importance unequal; and to kill and to allow to die are morally identical, since their moral effect is exactly the same. So any action (or inaction) which can be seen in advance to result in the death of one or more persons can be justified only if (a) those persons are themselves intentionally threatening the life or autonomy of other persons, or (b) the death of a smaller number of people is necessary in order to save the lives of a larger number, or (c) the persons have autonomously decided that their lives are no longer of value to them.

If this is applied to medical ethics, the following conclusions, among others, can be drawn:
1. Abortions and experiments on human embryos present no moral problem, since no person is involved.

2. The withholding of treatment and/or nourishment from severely handicapped children is morally identical to killing them: indeed, worse, since it causes them more suffering. As such, there is at least a strong presumption that it is wrong.

3. Voluntary euthanasia, freely chosen, is not wrong.

4. On the other hand, the involuntary euthanasia practised by the government, whose failure to provide adequate health care makes it morally responsible for the resulting deaths, is certainly morally wrong.

5. The failure to provide patients with adequate information to make autonomous decisions is wrong.

6. There should be a very strong presumption against overriding patients' expressed wishes, unless there is good reason to think that defects of selfcontrol, reasoning or information make them non-autonomous.

7. No sexual practice or mode of bringing children into the world can be morally wrong unless it violates the autonomy of another person or causes them undesired physical or mental suffering.

8. The value of a life is given by its importance for its possessor, not by its usefulness to others: hence the lives of the old, as long as they wish to live, are just as important morally as those of the young.

There is of course no space to comment on all these points. Instead, I would like to draw attention to two possible areas of dispute, one regarding an internal inconsistency, one regarding the basic premiss.

The internal problem is the status of 'potential persons', ie beings that are not yet persons but may be expected to become persons. With regard to fetuses, John Harris denies the validity of such a notion altogether. But he holds elsewhere that we are obliged to keep children alive until they become autonomous persons. This seems equivalent to treating children, morally, as potential persons: if children, why not unborn children?

The second problem is the basic premiss. There is a powerful alternative ethical view, according to which life is of value in itself, not only because it is valued by its possessor. If such a view is taken, particularly if it is combined with a view that the full development of various kinds of life, particularly human development, is of special value, some, though by no means all, of JohnT Harris's conclusions will be disputable. For example, abortion and experimentses on embryos will raise serious moral problems; some sexual practices may bes seen as incompatible with humano dignity or development (if, for example, $\bar{\sigma}$ it is the case that promiscuity leads to $\overline{\text {. }}$ insensitivity and hard-heartedness); $\overrightarrow{\widetilde{\Phi}}$ and in some cases, though withholding nourishment from infants is not one of s them, letting die may show a respect for humanity that killing does not (to care.for the dying by relieving their suffering $\vec{\omega}$ and not intervening to prolong life mayo be very different from giving them $\mathrm{a} 3 \overline{3}$ lethal injection). The two views do yield ${ }^{\mathbb{D}}$ different, though not totally different $\overrightarrow{-}$ conclusions: how to choose betweenit them is difficult and complex.

What is true on either view is, first, $\vec{\omega}$ that the life and autonomy of every음 human being is important, and, second, - that ethical questions can be handled $\square$ rationally and objectively. Even if one were to disagree with everything else in this book, one should be very grateful for the affirmation of these two points, and for the fact that it thereby drives $\overrightarrow{0}$ one more nail into the coffin of ethishlo subjectivism. Probably few people agree with everything in the book; everyone seriously interested in medie ethics should read it.

A H LESSER

Department of Philosophy, 음 University of Manchester, 으 Oxford Road, Manchester M13 9PL $\overrightarrow{\bar{O}}$

\section{Whose Body is It? The Troubling Issue of Informed Consent}

Carolyn Faulder, London, 158 pages, $£ 3.95$, Virago, 1985.

In the first section of this timely book $\frac{D}{2}$ the reader is treated to crisp definitions of the main concepts surroundingN informed consent. Legal, moral and historical meanings are analysed with a clarity which makes this book a pleasure to read. The principle of autonomy is pinpointed as the key to informed consent. This means doctors enabling patients to give their informed consente by offering access to the relevant information pertaining to them.

There is a romantic tradition in this country that there should be a rein on the law intervening in socia $\mathbb{B}$ relationships which are seen as private $\bar{\sigma}$ Doctors are proud of the way that their patients trust them, even when they lie, 